PREPARED FOR THE U.S. DEPARTMENT OF ENERGY, UNDER CONTRACT DE-AC02-76CH03073

PPPL-3724

PPPL-3724

UC-70

Diagnostics Plan for the National Compact

Stellarator Experiment

by

D. Johnson, T. Brown, H. Neilson, G. Schilling, H. Takahashi, M. Zarnstorff, M. Cole, E. Lazarus, and M. Fenstermacher

July 2002

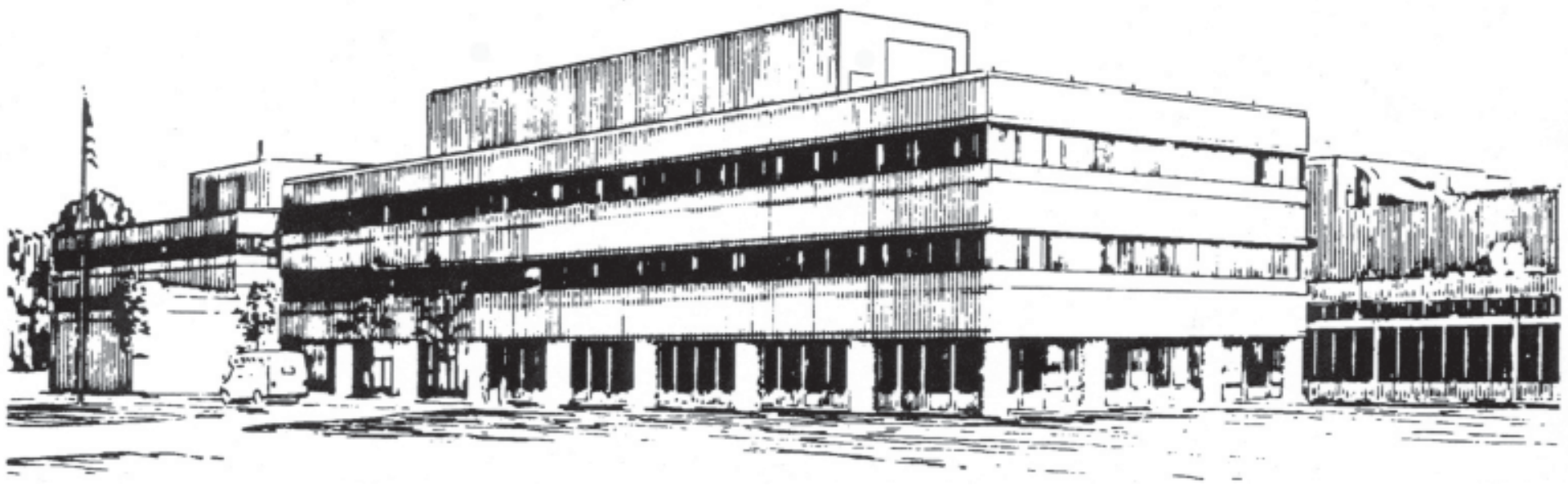

PRINCETON PLASMA PHYSICS LABORATORY PRINCETON UNIVERSITY, PRINCETON, NEW JERSEY 


\section{PPPL Reports Disclaimer}

This report was prepared as an account of work sponsored by an agency of the United States Government. Neither the United States Government nor any agency thereof, nor any of their employees, makes any warranty, express or implied, or assumes any legal liability or responsibility for the accuracy, completeness, or usefulness of any information, apparatus, product, or process disclosed, or represents that its use would not infringe privately owned rights. Reference herein to any specific commercial product, process, or service by trade name, trademark, manufacturer, or otherwise, does not necessarily constitute or imply its endorsement, recommendation, or favoring by the United States Government or any agency thereof. The views and opinions of authors expressed herein do not necessarily state or reflect those of the United States Government or any agency thereof.

\section{Availability}

This report is posted on the U.S. Department of Energy's Princeton Plasma Physics Laboratory Publications and Reports web site in Fiscal Year 2002. The home page for PPPL Reports and Publications is: http://www.pppl.gov/pub_report/

DOE and DOE Contractors can obtain copies of this report from:

U.S. Department of Energy

Office of Scientific and Technical Information

DOE Technical Information Services (DTIS)

P.O. Box 62

Oak Ridge, TN 37831

Telephone: (865) 576-8401

Fax: (865) 576-5728

Email: reports@adonis.osti.gov

This report is available to the general public from:

National Technical Information Service

U.S. Department of Commerce

5285 Port Royal Road

Springfield, VA 22161

Telephone: 1-800-553-6847 or

(703) 605-6000

Fax: (703) 321-8547

Internet: http://www.ntis.gov/ordering.htm 
Contributed paper for the $14^{\text {th }}$ Annual High Temperature Plasma Diagnostics Conference, Madison, Wisconsin, July 2002

\title{
Diagnostics Plan for the National Compact Stellarator Experiment
}

\author{
D. Johnson, T. Brown, H. Neilson, G. Schilling, H. Takahashi, and M. Zarnstorff \\ Princeton Plasma Physics Laboratory, Princeton, NJ 08540 \\ M. Cole, E. Lazarus \\ Oak Ridge National Laboratory, Oak Ridge, TN \\ M. Fenstermacher \\ Lawrence Livermore National Laboratory, Livermore, CA 94550
}

\begin{abstract}
The National Compact Stellarator Experiment (NCSX) is a stellarator-tokamak hybrid seeking to combine the good confinement, high beta and moderate aspect ratio of the tokamak with the quasi-steady-state operation and good stability properties of the stellarator. A preliminary list of measurement requirements, intended to satisfy the needs of the phased research plan, provides the basis for a full complement of plasma diagnostics. It is important to consider this full set, even at this early stage, to assess the adequacy of the stellarator design for diagnostic port access. The 3-D nature of the plasma is a measurement challenge, as is the necessity for high spatial resolution to assess the quality of magnetic surfaces. Other diagnostic requirements include the need
\end{abstract}


for re-entrant views that penetrate the cryostat, for a convenient e-beam probe for field line mapping, and for a diagnostic neutral beam for active spectroscopy.

\section{Introduction}

The mission of the National Compact Stellarator Experiment (NCSX) is to use the flexibility of 3-D shaping to combine the best features of stellarators and tokamaks. The project seeks to demonstrate conditions for high-beta, disruption-free operation by using externally generated helical fields at low aspect ratio in a quasi-axisymmetric configuration with significant bootstrap current. This configuration has 3 periods with $\mathrm{R} /\langle\mathrm{a}\rangle=4.4$ and $\langle\kappa\rangle=1.8$, and is produced by 18 modular coils ( 3 types), supplemented by a PF coil set and a weak TF set for flexibility. A set of external trim coils is planned to suppress $\mathrm{m}=2$ islands. All coils are cooled to $\mathrm{LN}_{2}$ temperature between shots within a cryostat. Many of these features appear in the cutaway view of NCSX shown in Fig. 1.

The configuration has been numerically optimized to be passively stable at $\beta=$ $4.1 \%$ to kink, ballooning, vertical, Mercier, and neoclassical-tearing modes, without conducting walls or feedback systems. With $\mathrm{R}=1.4 \mathrm{~m}, \mathrm{~B}=1.2-1.7 \mathrm{~T}$, the design features the capability to accommodate pulse lengths up to $1.2 \mathrm{sec}$ and $6-12 \mathrm{MW}$ of heating, consisting of both tangential neutral beam and high field launch RF. NCSX is predicted to achieve central $\mathrm{T}_{\mathrm{e}}(0), \mathrm{T}_{\mathrm{i}}(0) \sim 1.8 \mathrm{keV}$ at $\mathrm{n}_{\mathrm{e}} \sim 7 \times 10^{19} \mathrm{~m}^{-3}$, corresponding to $\beta \sim 4 \%$. The conceptual design for this device was successfully reviewed in May 2002, and the project path leads to first plasma in March $2007 .{ }^{1}$

This paper describes the conceptual plan for diagnostic integration on NCSX. At this early stage, a top priority is to assure adequate diagnostic access is available in the 
design of the core machine. We present a preliminary vision of the diagnostic complement needed to satisfy the needs of the anticipated research program, along with an initial evaluation of the diagnostic access available in the current design. Finally we present short discussions of some challenges/opportunities for some specific diagnostic systems.

\section{Integration of Diagnostics with Research Plan}

A Research Plan was developed for the Conceptual Design. (For a complete listing of research topics within each phase and many other details of the conceptual design, see ref. 1) The six phases are listed in Table 1, along with the associated measurement needs identified to address the research topics.

Vacuum and coil system shakedown occurs in the Initial Operation phase lasting $\sim 1$ month, with a goal of achieving a plasma with toroidal current of $\mathrm{I}_{\mathrm{p}}>25 \mathrm{kA}$. The magnetic diagnostics needed to control the plasma would be debugged during this phase, and several other diagnostics would be implemented for basic monitoring, as indicated in Table 1.

This would be followed by a $\sim 6$ month period for vacuum-field-mapping studies to verify the quality of the magnetic surfaces and identify errors in the design or assembly of the coil systems. A variety of vacuum configurations would be probed, with the coils first at room temperature and then cooled to normal operating temperature. Included for funding within the NCSX Project are diagnostics needed to verify that the core device has met its engineering goals. These are the diagnostic systems listed for phases 1 and 2 .

Control of plasma position and shape is a primary goal of the Ohmic phase. The diagnostics listed in Table 1 would also permit an assessment of the effect of 3-D shaping 
on global confinement, the dependence of the $n_{e}$ and $T_{e}$ profiles on iota, $I_{p}$, and trim coil current, and the impact of plasma contact position on plasma performance.

The mission elements begin to be addressed more directly in the phase 4 , when 3 MW of tangential neutral beam heating is commissioned from 2 beamlines. This Initial Auxiliary Heating campaign, which is envisioned to last $\sim 2$ years, will explore NCSX flexibility, plasma confinement, and stability at moderate $\beta$. The diagnostics listed for Phase 4 would permit local transport and stability analysis, in addition to a variety of other topics planned for this phase. Discharge evolution control to produce current profiles approximating the bootstrap profile will be tested. The trim coils will be used for controlled studies of rotation damping and neoclassical tearing modes. Fast ion confinement and influence on MHD will be evaluated. The edge and SOL will be characterized at moderate power.

The goal of the Confinement and High Beta Phase is to extend enhanced confinement regimes and investigate high beta stability with a full complement of $6 \mathrm{MW}$ from 4 sources and/or megawatt-level RF heating. This multi-year phase will also feature divertors for power and particle handling. Many of the research topics planned for this phase will utilize diagnostics previously installed. New diagnostics will be needed for characterizing the divertor and for studying turbulence, and its role in determining transport.

The Long Pulse phase feature heating system upgrades to allow pulse lengths of $1 \mathrm{sec}$, and power up to $12 \mathrm{MW}$, including possible upgrades of PFC's and divertors for improved power and particle handling. These upgrades should permit equilibration of the 
current profile to the bootstrap current and documentation of high-beta, disruption free operation for longer pulses.

The plan for research topics and associated diagnostic implementation will evolve as the project moves forward through the detailed design and construction phases. Preliminary measurement requirements, which help define the diagnostic needs derived from the research topics, and include specifications for spatial/temporal resolution and accuracy, have been developed in ref. 1 for the diagnostics listed in Table 1.

\section{Diagnostic Access Issues}

Diagnostic access has been given high priority in the design of NCSX. In the year between the Physics Validation Review and the Conceptual Design review, significant design changes in both the TF coils/supports and the cryostat were driven largely by a desire to improve diagnostic access. Port extensions permit diagnostic access through the cryostat and into the vacuum vessel. In the present design, these extensions are positioned on radial planes with their axes aimed nominally at the magnetic axis, in locations where they would clear modular coils, TF and PF coils. Positioning the TF coils at the mean toroidal position of the modular coils optimizes the space for the extensions. Along the length of a particular extension, the position of the vacuum seals would be outboard of the modular coil support "shell", but could be inboard of the cryostat boundary. This flexibility is facilitated by a close-fitting, conformal cryostat featuring removable panels that can be tailored to diagnostic space needs. This will permit some port extensions to be made shorter, and will open up more space within the cryostat perimeter. Nonetheless, the extension lengths will drive the design of many diagnostics to compact, re-entrant systems. In addition, bakeout $\left(350^{\circ} \mathrm{C}\right.$ for carbon $\mathrm{PFCs}$ 
and $150^{\circ} \mathrm{C}$ for vacuum vessel) and normal operation with coils cooled will subject frontend assemblies to temperature excursions which may necessitate active regulation.

The number of ports available for diagnostics appears adequate. The present design has 96 ports, including 4 for neutral beam injectors. Approximately 60 of these ports are allocated to the diagnostics in Table 1. Additional ports can accommodate auxiliary systems (fueling, wall conditioning, etc.) and future diagnostic needs. The most urgent near-term diagnostic activity is to optimize the orientation of the ports for some specific critical diagnostic views, perhaps deviating from the constraints that the port axes lie on radial planes and are directed to the magnetic axis.

\section{Magnetics}

In addition to the vacuum transform, the target NCSX plasma has a significant poloidal flux contribution from the bootstrap current, beam-driven current, and ohmic current. There is little experience controlling the flux evolution of such a plasma in 3-D, from discharge initiation to the high-beta phase. As part of the preliminary design, detailed modeling is planned to ascertain the optimum number, type, and placement of the sensors needed for equilibrium reconstruction and plasma control. The computational tools development to perform this analysis will be funded by the NCSX Program, collaborating with other stellarator groups and building upon existing tools. Rough estimates indicate that approximately 100 sensors of several different types will be required initially.

The magnetic sensors will likely include diamagnetic loops, flux loops, saddle loops, Rogowski coils and B-dot coils which will provide signals necessary to determine the internal magnetic field geometry using an 3-D equilibrium reconstruction code. 
Because of the strong shaping in NCSX plasmas, such a reconstruction can provide important information on profiles of plasma pressure and toroidal current density.

There is adequate clearance in the device design to mount magnetic sensors. There is a minimum clearance of $50 \mathrm{~mm}$ between the back of the PFC panels and the inner surface of the vessel. The minimum clearance between the outside of the vessel and the modular coils is $25 \mathrm{~mm}$. In most regions around the vacuum vessel, clearances exceed these values.

\section{Vacuum Field Mapping}

The traditional mapping technique involves an electron beam that lights up a fluorescent mesh or movable fluorescent rod as the beam makes many traverses along a field line. ${ }^{2,3,4}$ Light is detected by a CCD camera located at a suitable viewing window, with rather inefficient collection of the emitted light. To increase the sensitivity and time response, we are investigating other methods, which gather more of the light from the mesh or rod by collecting the light locally, perhaps with an array of vacuum compatible, phosphor-coated fiber optics. The fibers would relay the light from the strike points through a window to a high-dynamic-range CCD camera. Design goals include deployment of the probe without breaking vacuum, variable electron energy, and a spatial resolution of $2 \mathrm{~mm}$. Careful metrology will reference the array to machine coordinates. Strike points will be compared to expectations of a code, which will compute the beam trajectory for given coil currents. Magnetic island structures will be investigated at reference vacuum configurations, and the influence of trim coil currents will be assessed. 


\section{Compact SXR arrays}

$\mathrm{X}$-ray tomography using a large number of sightlines in multiple fan arrays is a powerful technique for investigating MHD mode structure. Such arrays have been used on both tokamaks and stellarators, typically with extensive coverage in one or two poloidal cross-sections. $^{5} \quad$ In order to achieve such coverage on NCSX, it will be necessary to install compact arrays inside the vacuum vessel, between the first wall and the vacuum vessel. One example of such an implementation is shown in Fig. 2.

Currently, there is not a design available for the array module that is compact enough to fit within the $50 \mathrm{~mm}$ space constraint between the first wall and the inner vacuum vessel wall. It may be necessary to enlarge the vessel locally to accommodate realistic SXR array sizes. Using available technology, a minimum clearance of $\sim 110$ $\mathrm{mm}$ would be needed. It would be preferable to do this in a section near the oblate crosssection $(v=1 / 2)$ such as that in Fig. 2, to take advantage of the flux expansion at this location.

\section{Thomson Scattering}

Because of the moderate density and relatively low magnetic field on NCSX, it will not be possible to use conventional ECE techniques for measuring $T_{e}(R, t)$. Thus Thomson scattering will be a key diagnostic, providing time-resolved profiles for $\mathrm{T}_{\mathrm{e}}$ and $\mathrm{n}_{\mathrm{e}}$. At the same time, high spatial resolution would also be very useful, for example, to characterize island and 'filament' structures. The current concept for this diagnostic uses a Nd:YAG laser system with a laser repetition rate of $\sim 100 \mathrm{~Hz}$. Twenty filter polychromators will be used with 4 spectral channels each. Light from 3 positions in the 
plasma will be relayed via 3 different fiber optic bundle lengths to each polychromator. Fast transient recorders $(4 \times 20=80$ channels at $1 \mathrm{Gs} / \mathrm{s})$ will resolve the three timemultiplexed signals from the APD detectors, following concepts developed for RFX, MAST, and JET. ${ }^{6,7}$ In this way a 60 point spatial profile will be recorded for each laser pulse, with a spatial resolution of $\sim 1 \mathrm{~cm}$. The laser is fired vertically at the "banana" symmetry plane, and imaged with a high throughput collection system at the outer midplane, as shown in figure 3 .

\section{Active Spectroscopy}

The NCSX heating beams inject nearly parallel to flux surfaces. Because of the large beam cross-section, this means that viewing the intersection of the beam with the core plasma region from any position results in sightlines that cross many flux surfaces, and hence poor spatial resolution. In principal, information from many views from different angles could be inverted to regain localization, this would be very difficult in the 3-D geometry of NCSX.

A diagnostic neutral beam (DNB) injected as shown in Fig. 3, could be used for active spectroscopy. A charge exchange recombination spectroscopy (CHERS) system, viewing carbon charge exchange emission, would then be used for profile measurements of $T_{i}, v_{\theta}$ and $v_{\phi}$. The DNB could also be used for iota profile measurements with an motional Stark effect (MSE) polarimeter system viewing $\mathrm{H}_{\alpha}$ emission. A compact DNB and laser will be used with a second MSE polarimeter using laser-induced $\mathrm{H}_{\alpha}$ fluorescence (LIF). ${ }^{9}$ The two polarimeters should permit independent determinations of $\mathbf{J}$ and $\mathrm{E}_{\mathrm{r}}$. Figure 3 shows possible views for these active spectroscopy diagnostics. As 
indicated in the figure, further work is needed in the definition of port orientations to achieve suitable viewing geometries.

\section{Summary}

At the concept level, the NCSX project has a well-articulated research plan, and has identified a preliminary list of diagnostics phased to support these experiments. The detailed design is proceeding with an eye to providing adequate diagnostic access. As this diagnostic plan evolves, it will clearly benefit from community input. Diagnostics are entry points for establishing collaborative participation in NCSX, as they have on many other devices. Diagnostic Working Groups will be an important component of the NCSX Research Forums, which will begin in FY2005, and will serve to identify experts interested in developing diagnostics, and to seek and encourage new diagnostic development that might benefit NCSX.

Acknowledgements - This research was supported by the U.S. Department of Energy under contract: DE-AC02-76CH03073.

\section{References:}

${ }^{1}$ See http://www.pppl.gov/ncsx/Meetings/CDR

${ }^{2}$ M. Yamada, et al., Rev. Sci. Instrum. 61, 686 (1990)

${ }^{3}$ H. Lin, et al., Rev. Sci. Instrum. 66, 464 (1995)

${ }^{4}$ M. G. Shats, et al., Rev. Sci. Instrum. 66, 1163 (1995)

${ }^{5}$ A.Weller, C. Gorner, and D. Gonda, Rev. Sci. Instrum. 70, 484 (1999)

${ }^{6}$ L. Guidicotti, et al., Rev. Sci. Instrum. (these proceedings)

${ }^{7}$ M.Walsh, et al., Rev. Sci. Instrum. (these proceedings)

${ }^{8}$ P. Nielsen and R. Pasqualotto, JET-EP diagnostic proposal for high resolution Thomson scattering system

${ }^{9}$ J. Foley, et al., Rev. Sci. Instrum. (these proceedings) 


\begin{tabular}{|c|c|}
\hline \multirow{2}{*}{\multicolumn{2}{|c|}{$\begin{array}{l}\text { PHASE/MEASUREMENT DIAGNOSTIC TECHNIQUE } \\
\text { 1. Initial Operation }\left(\mathbf{1 5 0}^{\circ} \mathrm{C} \text { bake, GDC }\right)\end{array}$}} \\
\hline & \\
\hline$I_{p}$ & Roqowski coils \\
\hline conductivity & flux loops + Ip \\
\hline boundary position and shape & magnetics + 3-D EFIT \\
\hline total stored energy & diamagnetic loop \\
\hline image of plasma/wall & video cameras with filters \\
\hline & $1 \mathrm{~mm}$ interferometer \\
\hline \multicolumn{2}{|l|}{ 2. Field Mapping (no plasma) } \\
\hline vacuum flux surfaces & $\begin{array}{l}\text { e-beam probe }+ \text { fluorescent } \\
\text { rod/screen probe }+ \text { high dyn. } \\
\text { range CCD camera }\end{array}$ \\
\hline \multicolumn{2}{|l|}{ 3. Ohmic ( 3 poloidal limiters) } \\
\hline $\mathrm{n}_{\mathrm{e}}$ profile & $\begin{array}{l}\text { FIR interfer./ polarim. } \\
\text { Thomson scattering }\end{array}$ \\
\hline $\mathrm{T}_{\mathrm{e}}$ profile & Thomson scattering \\
\hline $\mathrm{T}_{\mathrm{i}}$ profile & X-ray crystal spectrometer \\
\hline $\mathrm{P}_{\mathrm{rad}}$ profle & core foil bolometer array \\
\hline low $(m, n)$ MHD modes & multiple compact SXR arrays \\
\hline magnetic axis position & comp. SXR arrays + 3-D EFIT \\
\hline impurity identification & visible spectrometer \\
\hline impurity concentration & abs. UV spectroscopy \\
\hline$Z_{\text {eff }}$ profile & use Thomson scattering system \\
\hline hydrogen recycling & filtered 1D CCD camera \\
\hline \multicolumn{2}{|c|}{ 4. Initial Auxiliary Heating (3 MW NBI, PFCs, $350^{\circ}$ bake) } \\
\hline $\mathrm{T}_{\mathrm{i}}, \mathrm{v}_{\theta}, \mathrm{v}_{\phi}$ profiles & DNB+toroidal, poloidal CHERS \\
\hline iota profile & DNB+MSE polarim.+ 3-D EFIT \\
\hline higher $(m, n)$ MHD modes & additional compact SXR arrays \\
\hline flux surface topology & tang. $\mathrm{x}$-ray camera +3 -D EFIT \\
\hline fast ion loss & fast ion loss probe \\
\hline ion energy distribution & neutral particle analyser \\
\hline neutron flux & epithermal neutron detector \\
\hline high frequency $\mathrm{MHD}(<5 \mathrm{Mhz})$ & high frequency Mirnov coils \\
\hline first wall temperature & compact IR camera \\
\hline SOL $\mathrm{T}_{\mathrm{e}}$ and $\mathrm{n}_{\mathrm{e}}$ & movable Langmuir probe \\
\hline edge neutral pressure & $\begin{array}{l}\text { fast gauges } \\
6 \text { MW heating full divertor) }\end{array}$ \\
\hline $\begin{array}{l}\text { 5. Contmnement } \alpha \text { Beta Push } \\
\text { divertor Prad profile }\end{array}$ & divertor bolometer arrays \\
\hline divertor plate temperature & fast IR camera \\
\hline $\operatorname{target} \mathrm{T}_{\mathrm{e}}, \mathrm{n}_{\mathrm{e}}$ & plate mounted Langmuir probes \\
\hline core $n_{e}$ & fluctuation diagnostics TBD \\
\hline SOL/edge $T_{e}$ and $n_{e}$ & fast scanning edge probe \\
\hline core helium density & DNB + He CHERS system \\
\hline divertor target temperature & divertor thermocouples \\
\hline divertor recycling & divertor filtered CCD camera \\
\hline divertor impurity conc., flows & divertor UV spectroscopy \\
\hline
\end{tabular}
6. Long Pulse (pumped divertor) divertor $\mathrm{T}_{\mathrm{e}}, \mathrm{n}_{\mathrm{e}}$ profiles divertor Thomson scattering

Table 1 Research phases, measurement needs and diagnostics 


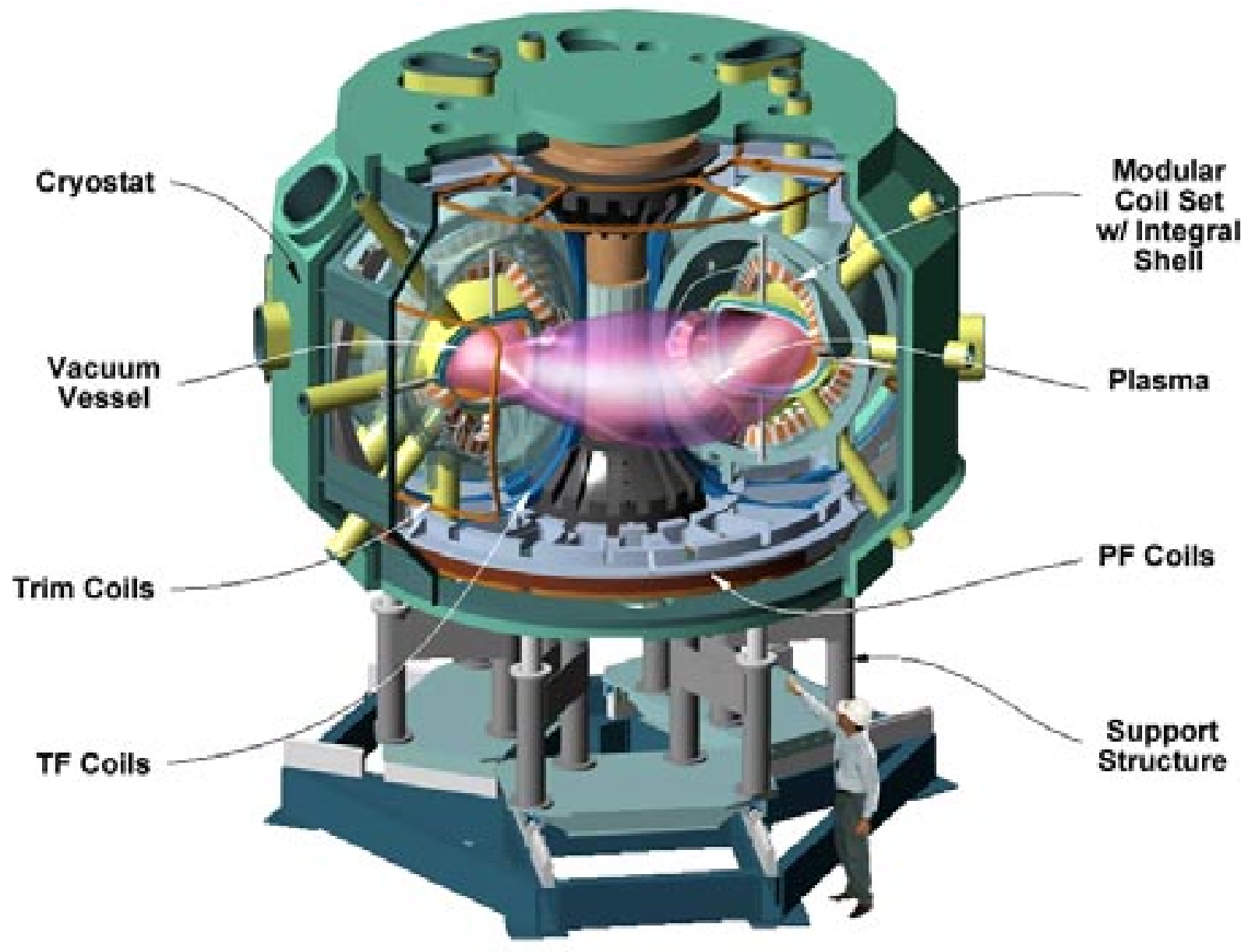

Figure 1 Cut-Away View of the Stellarator Core Assembly 


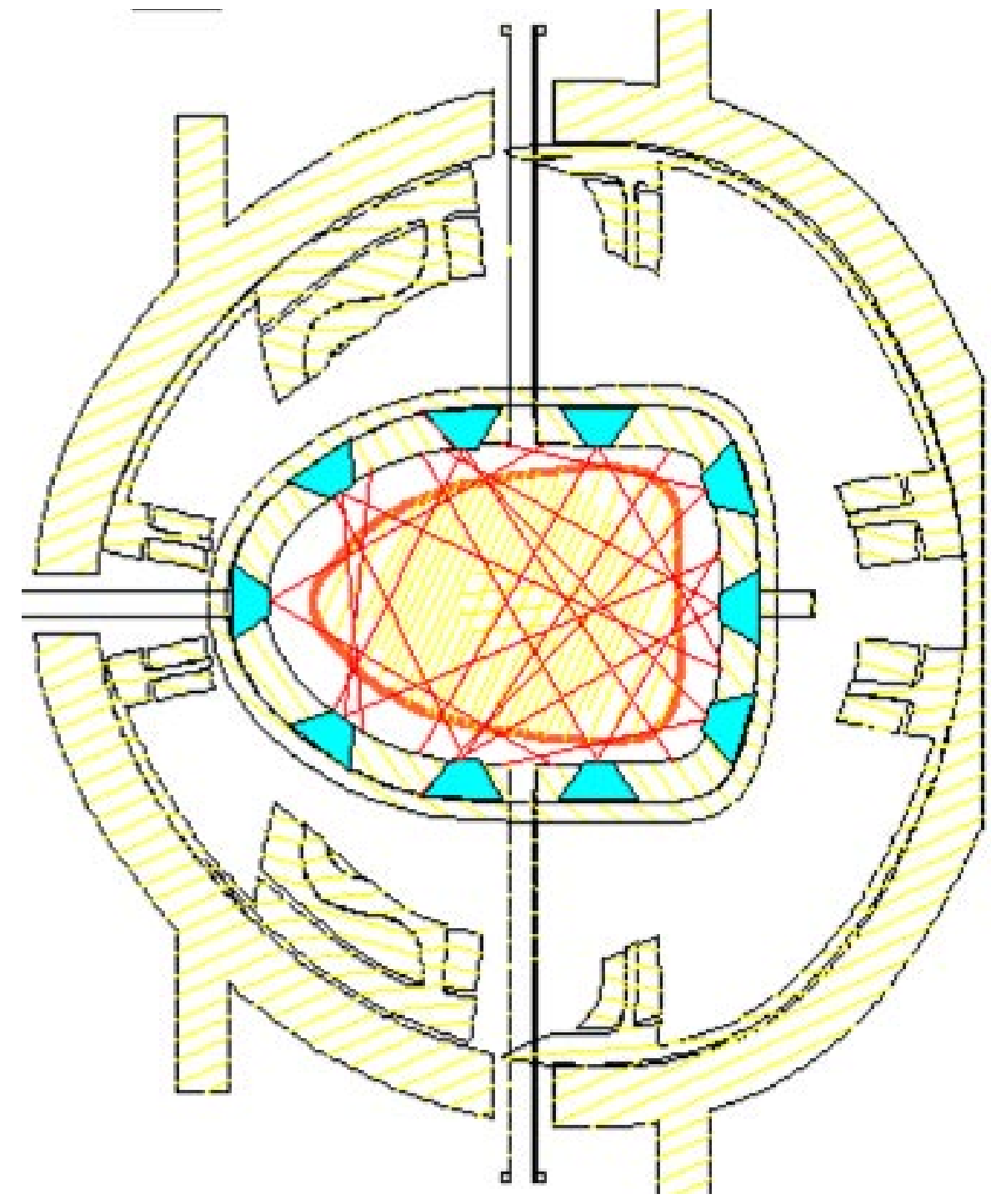

Figure 2 Viewing concept for compact in-vessel soft x-ray arrays 


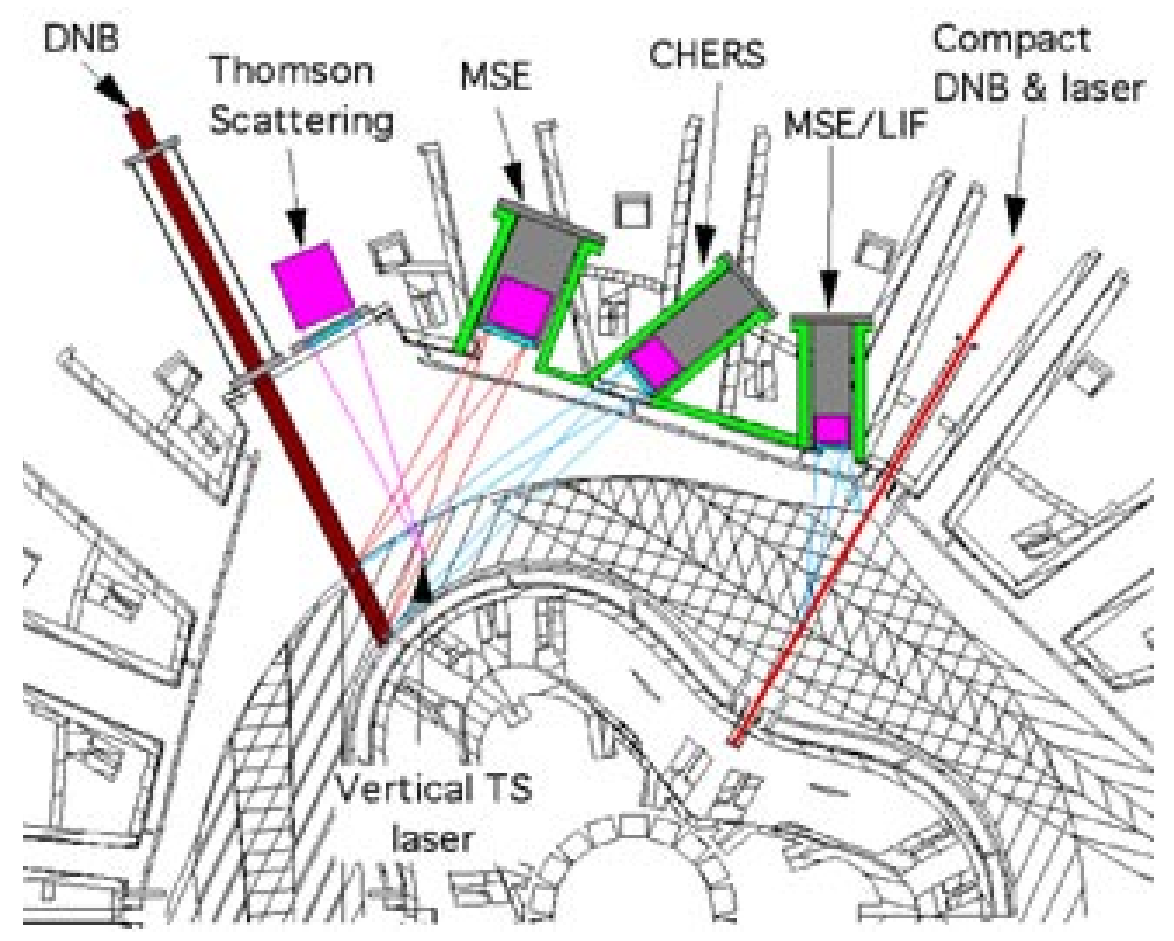

Figure 3 Midplane cut of NCSX showing concepts for viewing geometries for active spectroscopy and Thomson scattering. To provide suitable views, proposals to shorten and reorient port extensions are under consideration. 


\section{External Distribution}

Plasma Research Laboratory, Australian National University, Australia

Professor I.R. J ones, Flinders University, Australia

Professor J oão Canalle, Instituto de Fisica DEQ/IF - UERJ , Brazil

Mr. Gerson O. Ludwig, Instituto Nacional de Pesquisas, Brazil

Dr. P.H. Sakanaka, Instituto Fisica, Brazil

The Librarian, Culham Laboratory, England

Library, R61, Rutherford Appleton Laboratory, England

Mrs. S.A. Hutchinson, JET Library, England

Professor M.N. Bussac, Ecole Polytechnique, France

Librarian, Max-Planck-Institut für Plasmaphysik, Germany

J olan Moldvai, Reports Library, MTA KFKI-ATKI, Hungary

Dr. P. Kaw, Institute for Plasma Research, India

Ms. P.J . Pathak, Librarian, Insitute for Plasma Research, India

Ms. Clelia De Palo, Associazione EURATOM-ENEA, I taly

Dr. G. Grosso, Instituto di Fisica del Plasma, Italy

Librarian, Naka Fusion Research Establishment, J AERI, J apan

Library, Plasma Physics Laboratory, Kyoto University, J apan

Research Information Center, National Institute for Fusion Science, J apan

Dr. O. Mitarai, Kyushu Tokai University, J apan

Library, Academia Sinica, Institute of Plasma Physics, People's Republic of China

Shih-Tung Tsai, Institute of Physics, Chinese Academy of Sciences, People's Republic of China

Dr. S. Mirnov, TRINITI, Troitsk, Russian Federation, Russia

Dr. V.S. Strelkov, Kurchatov Institute, Russian Federation, Russia

Professor Peter Lukac, Katedra Fyziky Plazmy MFF UK, Mlynska dolina F-2, Komenskeho Univerzita, SK-842 15 Bratislava, Slovakia

Dr. G.S. Lee, Korea Basic Science Institute, South Korea

Mr. Dennis Bruggink, Fusion Library, University of Wisconsin, USA

Institute for Plasma Research, University of Maryland, USA

Librarian, Fusion Energy Division, Oak Ridge National Laboratory, USA

Librarian, Institute of Fusion Studies, University of Texas, USA

Librarian, Magnetic Fusion Program, Lawrence Livermore National Laboratory, USA

Library, General Atomics, USA

Plasma Physics Group, Fusion Energy Research Program, University of California at San Diego, USA

Plasma Physics Library, Columbia University, USA

Alkesh Punjabi, Center for Fusion Research and Training, Hampton University, USA

Dr. W.M. Stacey, Fusion Research Center, Georgia Institute of Technology, USA

Dr. J ohn Willis, U.S. Department of Energy, Office of Fusion Energy Sciences, USA

Mr. Paul H. Wright, Indianapolis, Indiana, USA 
The Princeton Plasma Physics Laboratory is operated by Princeton University under contract with the U.S. Department of Energy.

\author{
Information Services \\ Princeton Plasma Physics Laboratory \\ P.O. Box 451 \\ Princeton, NJ 08543
}

Phone: 609-243-2750

Fax: 609-243-2751

e-mail: pppl_info@pppl.gov

Internet Address: http://www.pppl.gov 